\title{
Community factors to promote parents' quality of child-nurturing life
}

\author{
Megumi Aoyama $\cdot$ Wei Chang-nian • \\ Koichi Harada $\cdot$ Kimiyo Ueda $\cdot$ Miyuki Takano • \\ Atsushi Ueda
}

Received: 8 January 2011 / Accepted: 20 August 2012/Published online: 6 October 2012

(C) The Japanese Society for Hygiene 2012

\begin{abstract}
Objectives The purpose of this study was to clarify the role of community factors in parents' quality of childnurturing life (QCNL).

Methods We developed a questionnaire to evaluate the degree of QCNL and determine the structural factors related to QCNL as community factors related to parents' QCNL derived from focus group interviews and the Delphi technique. The questionnaire also included the battery of the self-rating depression scale and Tsumori-Inage Infant's Developmental Test. Using the questionnaire, we then conducted a quantitative survey of parents whose children attended nursery schools in Kumamoto Prefecture. Factor analysis, calculation of the mean score and/or ratio to each item, Pearson's correlation coefficient, $t$ test, multiple regression analysis, and covariance structure analysis were performed.
\end{abstract}

M. Aoyama $(\bowtie) \cdot$ W. Chang-nian · A. Ueda

Department of Preventive and Environmental Medicine,

Kumamoto University Graduate School of Medicine,

1-1-1 Honjo, Kumamoto 860-8555, Japan

e-mail: megumi_aoyama@s7.kcn-tv.ne.jp

K. Harada

Department of Biomedical Laboratory Sciences,

Faculty of Life Sciences, Kumamoto University,

Kumamoto, Japan

K. Ueda

Department of Community Health Nursing,

School of Health Sciences, Kumamoto University,

Kumamoto, Japan

M. Takano

Department of Clinical Psychology,

Kyushu Lutheran College, Kumamoto, Japan
Results The questionnaire we developed consisted of seven items with 75 elements, involving ten elements as community factors. Subjects included 699 parents (mean age $33.6 \pm 5.4$ years) and 965 children (age range $0-6$ years). Factor analysis revealed that community factors consisted of five factors, such as "lifestyle rooted in the ground," "balance of housekeeping and work," "community network," "amenity," and "regeneration of life". These factors may be dominant in a rural area. Finally, we developed a structural model with "community factors," QCNL, QOL, and "child growth" by covariance structural analysis. The analysis revealed that community factors had a positive relation to parents' QCNL $(r=0.81, p<0.001)$ and that parental SDS score had a negative relation to parents' QCNL $(r=-0.59$, $p<0.001)$. The analysis did show that community factors were positively related to the sound growth of children.

Conclusion The covariance structure analysis revealed that community factors were associated with parents' QCNL, SDS, and "child growth."

Keywords Maternal and child health - Quality of child-nursing life · Qualitative study · Quantitative study

\section{Introduction}

According to the White Paper on Annual Health, Labour and Welfare issued by the Ministry of Health, Labour and Welfare of Japan [1], the traditional child-nurturing environment and daily life activities in a community have changed, and the maladaptation of child-nurturing parents and community populations to these changes may result in the development of various social problems, such as child abuse. Therefore, new approaches are urgently needed to improve the child-nurturing environment. 
Results from socio-scientific research [2-8] have indicated that various problems may be present in the childnurturing environment in Japan and that community bonds, so-called social cohesiveness, may play an important role in overcoming these problems. Research has also indicated that experiencing rich and various human relations with people of the same and different age groups from childhood onwards may be important for maturation of the personality. In addition, parents themselves are considered to have stress-reducing and relaxing effects on their children and play a major role in promoting the maturation of both parents and children, which is necessary for the development of child-nurturing abilities. These reports indicate that there may be a number of community factors that promote parents' quality of child-nurturing life (QCNL) in that community. In terms of the significance of community factors in promoting residents' health from rural areas, Ueda et al. [9] noted that a significantly lower frequency of low-birth-weight infants was seen in agricultural communities, suggesting that there may be some factors in these communities that improve the QOL of child-nurturing parents and reduce the occurrence of lowbirth-weight infants.

We therefore hypothesized that an important lifestyle for sound child-nurturing based on community factors is dominantly present in rural areas, such as a sustainable network and closeness to nature for sound child-nurturing. We hypothesized that: (1) since child-nurturing occupies most of the time of child-nurturing parents, QCNL is the most significant factor regulating their quality of life (QOL); (2) "community factors" are basic factors in a community that serve to achieve a desirable QCNL; (3) QCNL is also an effective factor to promote the sound growth of children.

On the basis of these hypotheses, we conducted a study to clarify the structure of community factors related to QCNL and the sound growth of children using both a qualitative and quantitative approach.

\section{Methods}

Development and components of the questionnaire

\section{Questionnaire for child-nurturing parents}

Basic elements of the questionnaire were derived from focus group interviews (FGI) $[10,11]$ and the Delphi technique [12]. We conducted FGI with three groups involving 27 child-nurturing parents at three nursery schools in Kumamoto Prefecture. The collected data from the FGI were summarized and applied to the PRECEDEPROCEED model [13]. We then conducted two-round
Delphi technique interviews involving 20 experts in maternal and child health to determine the order of priority concerning "behavior and lifestyle" in the model. The final questionnaire items according to the phase sequence of the PRECEDE-PROCEED model were as follows:

Phase 1. The battery of QCNL consisted of five items: (1) enjoying the sound growth of the child, (2) enjoying child-nurturing, (3) enjoying childnurturing by cooperating with the family, (4) enjoying child-nurturing with the entire community, and (5) enjoying child-nurturing by cooperating with a nursery school. The overall battery of items and six elements of QOL were developed from the "basic elements of the QOL” proposed by the Center for Health Promotion [13]. Here, QOL is defined as the "degree to which a person enjoys the important possibilities of his/her life", according to the definition by Renwick et al. [14].

Phase 2. As the participants of the FGI complained of strong feelings of stress regarding child-nurturing, the self-rating depression scale (SDS) devised by Hukuda and Kobayashi [15] was employed to evaluate the state of health on the aspect of stress.

Phase 3. Ten elements for "behavior and lifestyle" were finally decided upon by the Delphi technique. In addition, we settled on ten elements for "community factors" extracted by FGI as "environmental factors" in phase 3.

Phase 4. Enhancing factors consisted of 15 "predisposing factors," 15 "reinforcing factors," and 15 "enabling factors" corresponding to the elements for "behavior and lifestyle".

Thus, we made an original questionnaire composed of seven items with 77 elements along with the framework of the PRECEDE-PROCEED model, such as the items of (1) "QCNL" with five elements, (2) "overall QOL" and six elements for the subscales of QOL, (3) "behavior and lifestyle" with ten elements, (4) "community factors" with ten elements, and "enhancing factors" with three items of (5) "predisposing factors," (6) "reinforcing factors," and (7) "enabling factors", with 15 elements per item. Added to these items was a background information sheet on "QCNL," such as gender, age, family composition, educational background, situation of employment, housing conditions, and information concerning circumstances around the house.

Each element of the overall QOL, components of QOL, and QCNL was scored on five levels, with a score of 1 referring to the lowest level and a score of 5 referring to the highest level. Other scales, such as "behavior and 
lifestyle," "community factors," "predisposing factors," "reinforcing factors," and "enabling factors" were scored on four levels, where a score of 1 referred to "never," a score of 2 to "seldom," a score of 3 to "often," and a score of 4 to "always." The score was set in a manner that a higher score indicated a more favorable condition. The total score of each item was calculated by adding the score of each element that composed the respective item.

\section{Questionnaire for children}

A questionnaire for children was prepared to obtain information on child growth by asking questions associated with the developmental and clinical histories of the child. The Tsumori-Inage Infant's Developmental Test, widely used in Japan, was employed as an index of the sound growth of children $[16,17]$. This battery of questions can be used to measure the developmental quotient (DQ) of children aged 0-6 years through the answers of parent. It has five domains, such as "development of motor function," "development of attentive walking," "social development," and "development of language."

\section{Questionnaire survey}

\section{Subjects}

Governmental data from the Division of Maternal and Child Health and the Division of Statistics of Kumamoto Prefecture 2010 indicated that there were about 586 authorized nursery schools and 143 kindergartens in the prefecture. Authorized nursery schools were attended by $34,53,57$, and $58 \%$ of infants aged $0,1-2,3$ years, and 4-5 years, respectively, and kindergartens were attended by 29 and $33 \%$ of infants aged 3 and 4-5 years, respectively. These data indicate that over $90 \%$ of infants residing in Kumamoto Prefecture aged 3-5 years were attending authorized nursery schools and/or kindergartens. In addition some infants aged 0 and 1-5 years were attending non-authorized nursery schools. In total, $52.3 \%$ of the whole population of children aged 0-5 years were attending authorized nursery schools. This percentage indicates that parents sending their children to nursery schools were representative of the child-nurturing population in Kumamoto Prefecture. We selected parents whose children attended nursery schools as subjects of the present questionnaire survey.

Three locations of nursery schools were selected for the study: (1) those located in City A $(670,097$ of the total population), which is an urban area defined according to the classification of agricultural area by the Japanese Ministry of Agriculture, Forestry, and Fisheries [18]) as being in the middle part of the Prefecture; (2) those in City
B (37,093) (hilly farming area) in the south part of the Prefecture; (3) those in City C $(71,423)$ (flat farming area) in the north part of the Prefecture.

\section{Distribution and recovery of the questionnaire}

A request for participation in the survey was sent to all nursery schools in the chosen areas through the respective local governments. The survey was entrusted to the nursery schools that consented to participate and involved parents who consented to participate in the survey as well as their children (ages 0-6 years).

First, the objective and contents of the questionnaire survey were explained to the local governments of the study areas for permission for nursery schools in their areas to participate. Once granted, the request for the cooperation of the nursery schools was made through the local governments. A letter inviting parents to participate in the questionnaire survey was distributed to all parents at the selected nursery schools who consented to the survey. Only those parents who consented to participate completed the questionnaire. A set of documents consisting of the questionnaires for parents and their children, explanations of the protection of personal information and informed consent, and consent forms for each family was sealed in an envelope and distributed to the parents. Whether parents responded to the questionnaire was left to their own judgment, and all subjects were assured that there would be consequences should they respond or not. Completed questionnaire forms were sealed by the parents themselves and collected by a member of the research team who did not see the answers.

\section{Verification of the reliability and validity of the questionnaire}

To determine the reliability of the questionnaire, we examined internal coherence and stability by dividing subjects into two groups with even and odd identification (ID) numbers; the mean value of each item was then compared between two groups. We also compared Cronbach's $\alpha$ coefficient of each domain between the two groups.

The validity of the survey procedure was secured by employing methods of qualitative surveys with established validity and reliability, such as FGI, the Delphi technique, and the PRECEDE-PROCEED model.

The validity of the structural concept was evaluated by performing factor analysis for items of QOL and QCNL, "behavior and lifestyle," "predisposing factors," "reinforcing factors," "enabling factors," and "community factors." Factor analysis by the principal factor method and varimax rotation was performed, and items with a 
characteristic value of $\geq 1$ and a factor loading of $\geq 0.3$ were selected. In this process, items with a factor loading of $<0.3$ were eliminated if the investigators agreed that they did not necessarily affect QOL or "behavior and lifestyle"; then the questionnaire was reconstituted and Cronbach's $\alpha$ coefficient was calculated again.

\section{Analyses of investigation data}

Data from all of the subjects from the three cities were calculated [mean \pm standard deviation (SD)] for each item and for the total score of each domain.

The relationship between QCNL, overall QOL, and elements of QOL, as well as the relationship between "community factors" and each item were examined using Pearson's correlation coefficient. In terms of growth and development of children, the developmental age in months was calculated, and the DQ was determined in accordance with the manual of the Tsumori-Inage Infant's Developmental Test. The relationship between the DQ of children and parents' QOL by "community factors" was examined using Pearson's correlation coefficient.

The relationship between items of each phase of the PRECEDE-PROCEED model was tested by multiple regression analysis, an independent sample $t$ test of the mean of each phase score of the PRECEDE-PROCEED model, and DQ of the children.

Finally, to verify hypotheses by covariance structural analysis, tentative models were prepared repeatedly by combining ID numbers used in the Tsumori-Inage Infant's Developmental Test with parents' data to examine the relationships between "community factors," parents' QCNL and QOL, and children's growth and development. The structure showing the best fit was selected.

SPSS ver. 11.0J for Windows (SPSS, Chicago, IL) and Amos ver. 5.0 for Windows (Amos Development Corp., Mount Pleasant, SC) were used to analyze the data.

\section{Ethical considerations}

For participants in the FGI, the objective and contents of the survey were explained to nursery schools and consent to partake in FGI was obtained at each school. The objective and contents of the survey were explained to parents who consented to participate, and consenting parents were asked to sign forms concerning the protection of personal information and duty of confidentiality. All efforts were made to protect personal information. For participants in the Delphi technique, personal information was secured in accordance with the procedure of the Delphi technique [12]. For participants in the questionnaire survey, personal information and rights were strictly protected.
The Ethics Committee of Kumamoto University approved the present study.

\section{Results}

\section{Response rate}

Requests for participation in the survey were sent out to 160 nursery schools, and 41 consented (positive response rate: $25.6 \%$ ). The questionnaire was distributed to 750 of these nursery school, and responses were obtained from 732 (response rate: $97.6 \%$ ), of which 699 (95.5\%) were valid. The questionnaire for children was distributed to 1,036 children, and responses were obtained from 1,008 (response rate: $97.3 \%$ ), of which $965(95.7 \%$ ) were valid. The response rate (96.1-100\% per school) and the validity rate (94.1-97.3\%) were not different between schools.

The number of parents participating in the survey was not in agreement with the number of children because some parents had two or more children at the same nursery school.

Preliminary analysis to verify the validity and reliability of the questionnaire

Factor analysis to each phase working through the PRECEDE-PROCEED model indicated that each phase had three to five factors, as shown in Fig. 1. For example, it was indicated that the item of "community factors" with ten elements consisted of five factors, such as "lifestyle rooted in the ground ( 2 elements)," "balance of housekeeping and work (2 elements)," "community network (3 elements)," "amenity (1 element)," and "regeneration of life (2 elements)."

Through this process, the number of elements was reduced from 77 to 75 items; one element was deleted from "predisposing factors" and the other one from "enabling factors". The remaining 75 items were confirmed as the final questionnaire for the present study (see Fig. 1). The Cronbach's $\alpha$ coefficient of the final questionnaire revised through factor analysis was found to be 0.80 for QOL, 0.77 for QCNL, 0.74 for "behavior and lifestyle," 0.80 for "community factors," 0.78 for "predisposing factors," 0.86 for "reinforcing factors," 0.81 for "enabling factors," and 0.94 for total items, indicating high internal coherence and showing applicability for individual measurements according to the evaluation by Pope and Mays [11].

Using the final questionnaire, 699 parents were divided into two groups, those with even and those with odd ID numbers, and data of the two groups were compared. The two groups were confirmed to have the same mean value and deviation and/or component ratio in each item and also showed the same Cronbach's $\alpha$ coefficient for each item; 


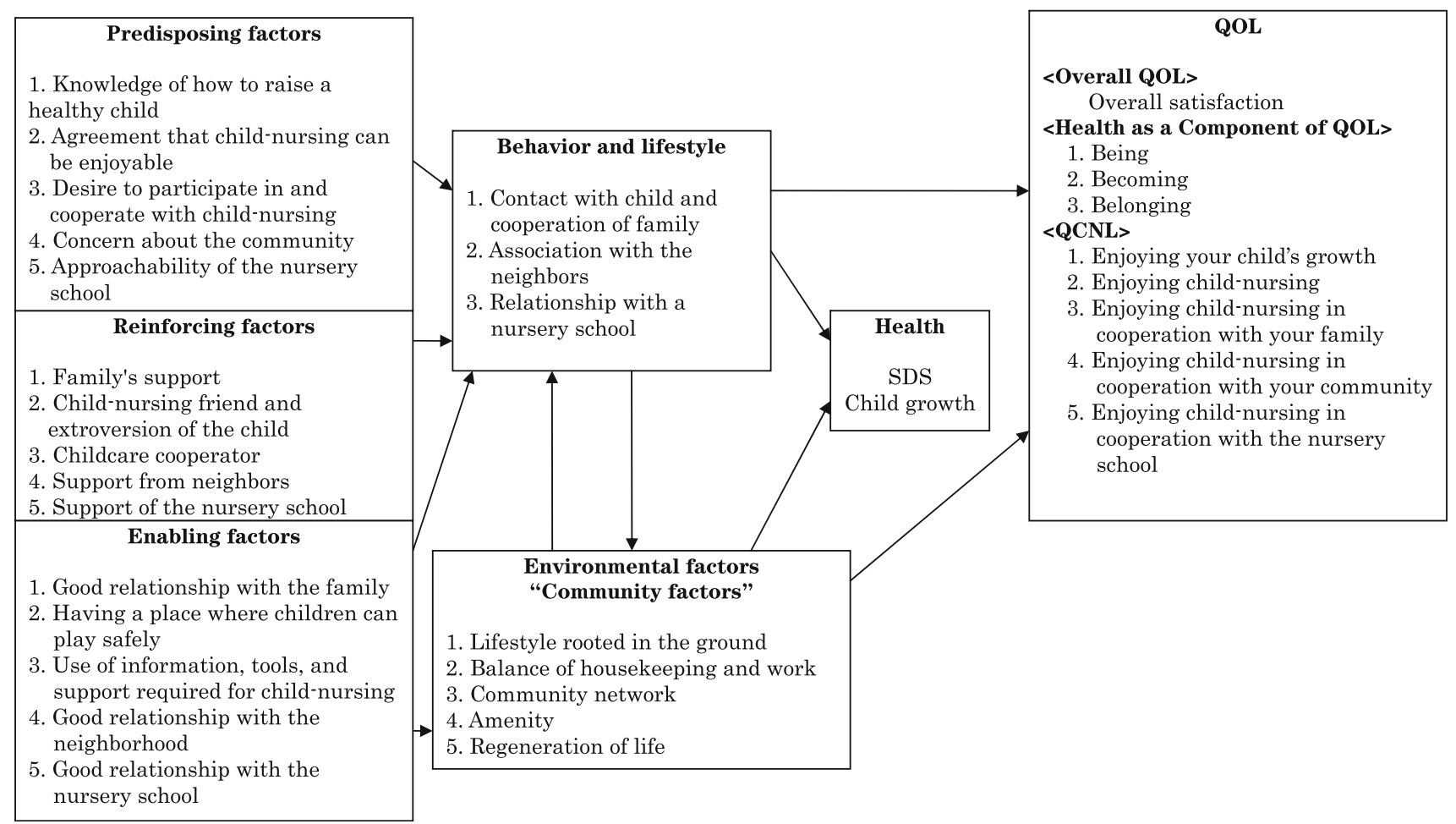

Fig. 1 The PRECEDE-PROCEED model of quality of child-nurturing life $(Q C N L)$ by factor analysis in the questionnaire used in the survey. $Q O L$ Quality of life, SDS self-rating depression scale

Table 1 Cronbach's $\alpha$ coefficients of each item by odd and even number groups (split-half method; odd-even method)

\begin{tabular}{|c|c|c|c|c|c|c|}
\hline \multirow[t]{2}{*}{ Each phase score } & \multirow[t]{2}{*}{ Number of items } & \multicolumn{2}{|c|}{ Odd number $(n=350)$} & \multicolumn{2}{|c|}{ Even number $(n=349)$} & \multirow[t]{2}{*}{$p(t$ test $)$} \\
\hline & & Cronbach's $\alpha$ & Mean \pm SD & Cronbach's $\alpha$ & Mean \pm SD & \\
\hline Overall QOL & 1 & & $3.67 \pm 0.94$ & & $3.76 \pm 0.92$ & n.s. \\
\hline Component of QOL & 6 & 0.8140 & $20.54 \pm 4.33$ & 0.7902 & $20.78 \pm 4.36$ & n.s. \\
\hline Overall NAC & 5 & 0.7741 & $20.38 \pm 2.98$ & 0.7632 & $20.47 \pm 2.82$ & n.s. \\
\hline Behavior and lifestyle & 10 & 0.7308 & $31.48 \pm 3.71$ & 0.7426 & $31.52 \pm 3.74$ & n.s. \\
\hline Predisposing factors & 15 & 0.7772 & $52.35 \pm 4.31$ & 0.7745 & $52.59 \pm 4.29$ & n.s. \\
\hline Reinforcing factors & 14 & 0.8503 & $45.42 \pm 6.23$ & 0.8557 & $45.36 \pm 6.25$ & n.s. \\
\hline Enabling factors & 14 & 0.8139 & $43.35 \pm 5.93$ & 0.7965 & $43.38 \pm 5.72$ & n.s. \\
\hline Community factors & 10 & 0.7935 & $28.00 \pm 5.04$ & 0.8017 & $27.35 \pm 5.12$ & n.s. \\
\hline Total items & 75 & 0.9430 & & 0.9440 & & \\
\hline
\end{tabular}

$S D$ Standard deviation, $Q O L$ quality of life, n.s. not significant

for example, Cronbach's $\alpha$ coefficient for total items of the questionnaire was 0.944 for the odd number group and 0.943 for the even number group (Table 1).

\section{Characteristics of the subjects}

Subject characteristics are summarized in Table 2. Among the 699 (mean age $33.6 \pm 5.4$ years) subjects of the present study, $93.3 \%$ were mothers.

In terms of family composition, the mean number of family members was $4.5 \pm 1.4$, and the mean number of children was $2.1 \pm 0.9$. For working conditions, the number of "working hours per week" were on average $34.9 \pm 12.8$, and $73.7 \%$ of parents worked "full-time."

Actual conditions of QCNL and related factors in child-nurturing parents and their children

The scores of each item of Qthe CNL and related factors by each item are shown in Table 3. Overall QOL scores were $3.71 \pm 0.93$. The score of the overall QCNL (5 items) was $20.43 \pm 2.90$ (4.09 per each element of that item). The 
Table 2 Subject characteristics

\begin{tabular}{|c|c|}
\hline Characteristics & $n(\%)$ or mean $\pm \mathrm{SD}$ \\
\hline Subjects & $699(100)$ \\
\hline Age (years) & $33.61 \pm 5.41$ \\
\hline \multicolumn{2}{|l|}{ Family composition } \\
\hline Number of family members & $4.50 \pm 1.36$ \\
\hline Number of children & $2.10 \pm 0.89$ \\
\hline Working hours per week & $34.94 \pm 12.81$ \\
\hline Duration of residence (years) & $8.70 \pm 9.35$ \\
\hline \multicolumn{2}{|l|}{ Kind of house } \\
\hline Detached house/rented house & $443(63.9)$ \\
\hline Apartment/condominium & $250(36.1)$ \\
\hline \multicolumn{2}{|l|}{ Education } \\
\hline Junior high school/high school & $317(45.7)$ \\
\hline Technical college/junior college & $280(40.4)$ \\
\hline University/graduate school & $96(13.8)$ \\
\hline \multicolumn{2}{|l|}{ Kind of work } \\
\hline Full-time & $514(73.7)$ \\
\hline Part-time & $132(18.9)$ \\
\hline Housewife & $51(7.3)$ \\
\hline \multicolumn{2}{|l|}{ Living environment around the house } \\
\hline There are fields & $847(78.7)$ \\
\hline There is a forest/wood & $349(50.4)$ \\
\hline There is the sea/river & 407 (58.6) \\
\hline Many houses & $278(40.5)$ \\
\hline Many tall buildings & $17(2.5)$ \\
\hline Noisy & $80(11.6)$ \\
\hline Bright at night & $66(9.6)$ \\
\hline Vegetable patches & $212(30.5)$ \\
\hline Gardens/fields & $437(62.7)$ \\
\hline
\end{tabular}

score of SDS was $39.87 \pm 7.74$ and showed that $50.4 \%$ of the subjects were over 40 , indicating light or more severe depression. The score of overall "behavior and lifestyle" (3 factors with 10 elements) was $31.5 \pm 3.72$ (3.15 per each element). The score of overall "community factors" (5 items with 10 elements) was $27.67 \pm 5.08$ (2.77 per each element).

Significance of "community factors"

The results of Pearson's correlation coefficients between scores of overall "community factors," overall QCNL, component of QOL, overall QOL, SDS, some factors related to daily life, and items of growth of children are shown in Table 4. Significant $r$ values were seen in overall "community factors" for "number of family members," "number of children," "duration of residence," and "age," with the exception of "working hours". Regarding overall QCNL, a significant $r$ value was only seen for "duration of residence." In contrast, there was no significant $r$ value between overall QOL and the component elements of QOL. For the SDS, a significant $r$ value was seen only for "age." Significant $r$ values were seen between overall "community factors" and each element of child development, such as "social development," "development of attentive walking," "development of motor function," and "development of language", with the exception of "development of lifestyle," and were also seen between overall QCNL and "development of attentive walking" and "social development". In contrast, significant $r$ values were not seen between overall QOL and each element of child development; nevertheless, these $r$ values were not seen to be high.

The results of multiple regression analysis by the forced entry method in two statistical models are shown in Table 5. Regarding model $1\left(R^{2}=0.409\right)$, with overall QCNL as a dependent variable, SDS, overall "behavior and lifestyle," and overall "community factors" as explanatory variables, significant positive " $\beta$ " was seen in overall QCNL to "behavior and lifestyle" $(\beta=0.332)$ and to "community factors" ( $\beta=0.189)$, and significant negative " $\beta$ " was seen to $\operatorname{SDS}(\beta=-0.272)$. Regarding model 2 $\left(R^{2}=0.513\right)$, with overall "behavior and lifestyle" as a dependent variable and overall " 3 enforcing factors" and overall "community factors" as explanatory variables, significant positive " $\beta$ " was seen to overall "predisposing factors" $(\beta=0.327)$, overall "enabling factors" ( $\beta=0.209)$, overall "reinforcing factors" $(\beta=0.192$,$) ,$ and "community factors" $(\beta=0.148)$.

Structural model for community child-nurturing combing "community factors," QCNL, and QOL of child-nurturing parents and growth of children

Finally, we performed covariance structural analyses by combining all items to clarify a structural model for a sound child-nurturing environment. Latent variables were "community factors," "child growth," "QCNL," and "component of QOL." The final model to have the highest goodness of fit $(\mathrm{CFI}=0.923$, RAMSEA $=0.058)$ is shown in Fig. 2. The model demonstrated that there may be a vector model for a sound environment for child-nurturing in the community, i.e., improved "community factors," increased QCNL, reduced SDS, increased QOL, and also the sound growth of children. The model revealed that community factors were positively related to parents' QCNL $(r=0.81, p<0.001)$ and negatively related to parental SDS score $(r=-0.59, p<0.001)$. On the other hand, the model showed that community factors related positively to the growth of children. However, QCNL and SDS were not directly related to growth of children. 
Table 3 Scores of each item according to the framework of the PRECEDE-PROCEED model $(n=699)$
SDS Self-rating depression scale, $Q C N L$ quality of childnurturing life
DOMAIN: phase

Mean SD Items: factor name (range of score) Elements

\begin{tabular}{|c|c|c|}
\hline \multicolumn{3}{|l|}{ QOL: phase 1} \\
\hline Overall QOL (1-5) & 3.71 & 0.93 \\
\hline Components of QOL (3-30) & 20.66 & 4.29 \\
\hline Being (1-10) & 7.20 & 1.78 \\
\hline Becoming (1-10) & 6.64 & 1.71 \\
\hline Belonging (1-10) & 6.78 & 1.69 \\
\hline Overall QCNL (5-25) & 20.43 & 2.90 \\
\hline Enjoying your child's growth (1-5) & 4.52 & 0.64 \\
\hline Enjoying child-nurturing (1-5) & 4.25 & 0.78 \\
\hline Enjoying child-nurturing in cooperation with your family (1-5) & 4.02 & 0.96 \\
\hline Enjoying child-nurturing in cooperation with your community (1-5) & 3.38 & 0.87 \\
\hline Enjoying child-nurturing in cooperation with the nursery school (1-5) & 4.25 & 0.75 \\
\hline \multicolumn{3}{|l|}{ HEALTH: phase 2} \\
\hline SDS (20-80) & 39.87 & 7.74 \\
\hline BEHAVIOR AND LIFESTYLE: phase 3 (10-40) & 31.50 & 3.72 \\
\hline Contact with the child and cooperation of the family (5-20) & 16.09 & 2.14 \\
\hline Association with the neighbors (3-12) & 9.07 & 1.55 \\
\hline Relationship with a nursery school (2-8) & 6.35 & 1.18 \\
\hline ENVIRONMENTAL FACTORS-COMMUNITY FACTORS: phase 3 (10-40) & 27.67 & 5.08 \\
\hline Lifestyle rooted in the ground (2-8) & 6.53 & 1.49 \\
\hline Balance of housekeeping and work (2-8) & 6.34 & 1.25 \\
\hline Community network $(3-12)$ & 6.87 & 2.00 \\
\hline Amenity (1-4) & 2.67 & 0.83 \\
\hline Regeneration of life $(2-8)$ & 5.27 & 1.72 \\
\hline PREDISPOSING FACTORS: phase 4 (15-60) & 52.48 & 4.30 \\
\hline Knowledge of how to raise a healthy child (3-12) & 11.52 & 0.84 \\
\hline Agreement that child-nurturer would be enjoyable (3-12) & 10.57 & 1.28 \\
\hline Desire to participate in and cooperate with child-nursing (3-12) & 11.16 & 1.98 \\
\hline Concern about the community $(3-12)$ & 8.90 & 1.80 \\
\hline Approachability of the nursery school (3-12) & 9.81 & 1.63 \\
\hline REINFORCING FACTORS: phase 4 (14-56) & 45.39 & 6.24 \\
\hline Family’s support (3-12) & 10.58 & 1.68 \\
\hline Child-nurturing friend and extroversion of the child (2-8) & 7.36 & 0.81 \\
\hline Childcare cooperator $(3-12)$ & 10.59 & 1.78 \\
\hline Support from neighbors $(3-12)$ & 6.74 & 2.72 \\
\hline Support of the nursery school $(3-12)$ & 10.01 & 2.08 \\
\hline ENABLING FACTORS: phase 4 (14-56) & 43.37 & 5.82 \\
\hline Good relationship with the family $(2-8)$ & 6.95 & 1.12 \\
\hline Having a place children can play safely $(1-4)$ & 3.10 & 0.91 \\
\hline Use of information, tools, and support required for child-nursing (6-24) & 17.39 & 3.10 \\
\hline Good relationship with the neighborhood (3-12) & 8.31 & 2.19 \\
\hline Good relationship with the nursery school (2-8) & 7.56 & 0.85 \\
\hline
\end{tabular}

\section{Discussion}

To clarify the significance of adopting "community factors" for child-nurturing parents and their children, we conducted a quantitative survey using a questionnaire developed by qualitative methods that verified the validity and reliability of the methods used, such as FGI $[10,11]$ and the Delphi technique [12].

We selected child-nurturing parents whose children were attending nursery schools from three cities located in 
Table 4 Relationships between community factors, QOL, QCNL, SDS, characteristics of the subject, and children DQ by the Pearson's correlation coefficient $(n=699)$

\begin{tabular}{|c|c|c|c|c|c|}
\hline Factors & Community factors & Overall QCNL & Component of QOL & Overall QOL & SDS \\
\hline \multicolumn{6}{|l|}{ Characteristics of the subjects } \\
\hline Parent's age & $0.122 * *$ & -0.033 & 0.039 & 0.063 & $-0.192 * * *$ \\
\hline The number of family members & $0.332 * * *$ & 0.072 & 0.039 & 0.010 & -0.048 \\
\hline The number of children & $0.212 * * *$ & -0.016 & 0.049 & 0.062 & -0.020 \\
\hline Working hours & -0.018 & 0.003 & -0.002 & 0.008 & -0.067 \\
\hline Duration of residence (years) & $0.144 * * *$ & $0.082 *$ & 0.075 & -0.029 & -0.075 \\
\hline \multicolumn{6}{|c|}{ Each factor of the PRECEDE-PROCEED model } \\
\hline Community factors & - & $0.475 * * *$ & $0.330 * * *$ & $0.278 * * *$ & $-0.391 * * *$ \\
\hline Overall QCNL & $0.475 * * *$ & - & $0.517 * * *$ & $0.438 * * *$ & $-0.483 * * *$ \\
\hline Component of QOL & $0.330 * * *$ & $0.517 * * *$ & - & $0.748 * * *$ & $-0.574 * * *$ \\
\hline Overall QOL & $0.278 * * *$ & $0.438 * * *$ & $0.783 * * *$ & - & $-0.505 * * *$ \\
\hline SDS & $-0.391 * * *$ & $-0.483 * * *$ & $-0.574 * * *$ & $-0.505 * * *$ & - \\
\hline Behavior and lifestyle & $0.546 * * *$ & $0.560 * * *$ & $0.445 * * *$ & $0.354 * * *$ & $-0.447 * * *$ \\
\hline Predisposing factors & $0.492 * * *$ & $0.433 * * *$ & $0.371 * * *$ & $0.286^{* * *}$ & $-0.426 * * *$ \\
\hline Reinforcing factors & $0.554 * * *$ & $0.528 * * *$ & $0.419 * * *$ & $0.296 * * *$ & $-0.420 * * *$ \\
\hline Enabling factors & $0.625 * * *$ & $0.495 * * *$ & $0.476 * * *$ & $0.374 * * *$ & $-0.488 * * *$ \\
\hline \multicolumn{6}{|c|}{ Children developmental quotient (DQ) ( $n=965$ number of children $)$} \\
\hline Development of motor function & $0.117 * *$ & 0.049 & 0.047 & 0.054 & -0.036 \\
\hline Development of attentive walking & $0.149 * * *$ & $0.090 * *$ & 0.048 & 0.033 & -0.044 \\
\hline Social development & $0.164 * * *$ & $0.081 *$ & $0.094 * *$ & 0.051 & -0.050 \\
\hline Development of lifestyle & 0.062 & 0.023 & 0.020 & 0.037 & 0.019 \\
\hline Development of language & $0.099 * *$ & 0.064 & 0.081 & 0.057 & $-0.092 * *$ \\
\hline
\end{tabular}

$* p<0.05, * * p<0.01, * * * p<0.001$

the north, middle, and south parts of Kumamoto Prefecture. In Kumamoto Prefecture, $52.3 \%$ of the whole population aged $0-6$ years was attending authorized nursery schools during the study period. We selected three cities that were representative of four area types according to the classification of agricultural areas by the Japanese Ministry of Agriculture, Forestry, and Fisheries [18], such as urban (City A), flat farming (City B), hilly farming (City C), and mountainous areas. Thus, the subjects in our study were representative of child-nurturing populations in Kumamoto Prefecture.

We developed a questionnaire by applying the PRECEDE-PROCEED model [13]. This model was developed with the aim to effectively apply intervention programs for health education and to evaluate the degree of improvement in the corresponding items. The model has been proven to be valid and useable for this intervention activity. The elements introduced into the model were essentially meant to be valid and applicable for evaluating the actual state of the corresponding problems. This is the reason that we adopted this model as the basis for our questionnaire.

As described in the Results, the final questionnaire we developed exhibited a high reliability and stability as follows. First, factor analyses of the questionnaire revealed that structures of QCNL, QOL, "community factors," "behavior and lifestyle," and "three enhancing factors" were clearly divided into three to five factors, respectively, and only two elements were invalid in 77 previous elements (see Fig. 1). Secondly, two randomly divided groups, comprising all subjects, obtained the same score in each item (Table 1). Thirdly, the Cronbach's $\alpha$ coefficient of each item was shown to be high enough to identify strong inner coherence in each item (Table 1). Fourthly, multiple regression analysis revealed that the component of the model was valid and reliable by indicating significant correlations from phase to phase (Table 5).

Characteristics and meaning of "community factors" developed for the present study

Factor analysis revealed that the evaluation battery for "community factors" with ten items developed through FGI consisted of five factors, such as "lifestyle rooted in the ground," "balance of housekeeping and work," "community network," "amenity," and "regeneration of life." 
Table 5 Relationships between each item from phase 1, phase 2, and phase 3 according to the PRECEDE-PROCEED model by multiple regression analysis (forced entry method) $(n=699)$

\begin{tabular}{lcc}
\hline Explanatory variable & $\beta$ & $p$ \\
\hline Model 1 (dependent variable: QCNL) & \\
Health (SDS) & -0.272 & 0.000 \\
Behavior and lifestyle & 0.332 & 0.000 \\
Community factors & 0.189 & 0.000 \\
$R^{2}$ & 0.409 & 0.000 \\
Model 2 (dependent variable: behavior and lifestyle) & \\
Predisposing factors & 0.327 & 0.000 \\
Reinforcing factors & 0.190 & 0.000 \\
Enabling factors & 0.209 & 0.000 \\
Community factors & 0.148 & 0.000 \\
$R^{2}$ & 0.513 & 0.000 \\
\hline
\end{tabular}

Model 1: Inter-relationships between QCNL (phase 1), health (SDS) (phase 2), and "behavior and life style" and "community factors" (phase 3)

Model 2: Inter-relationships between each item of "behavior and lifestyle" and "community factors" (phase 3) and three "enhancing factors" (phase 4)
These facts proved that the battery of "community factors" we developed has a significant meaning in terms of representing and evaluating the actual state of residents' lifestyle in the rural area. However, these "community factors" can also be fully utilized in urban areas by encouraging the establishment of close relationships between community residents and by establishing nature areas that are easy to use, such as parks and home gardens. It is also possible to incorporate these elements into development and welfare plans for urban districts. In fact, Motohashi and Kaneko et al. [19, 20] found that depression may be mitigated by close human relationships, i.e., social capital through the community-based suicide prevention program in Akita Prefecture.

Actual state of QCNL and related factors to QCNL in child-nurturing parents

The subjects were selected from three cities classified as urban, flat farming, and hilly farming areas, reflecting the actual situation of area types in Kumamoto Prefecture. As

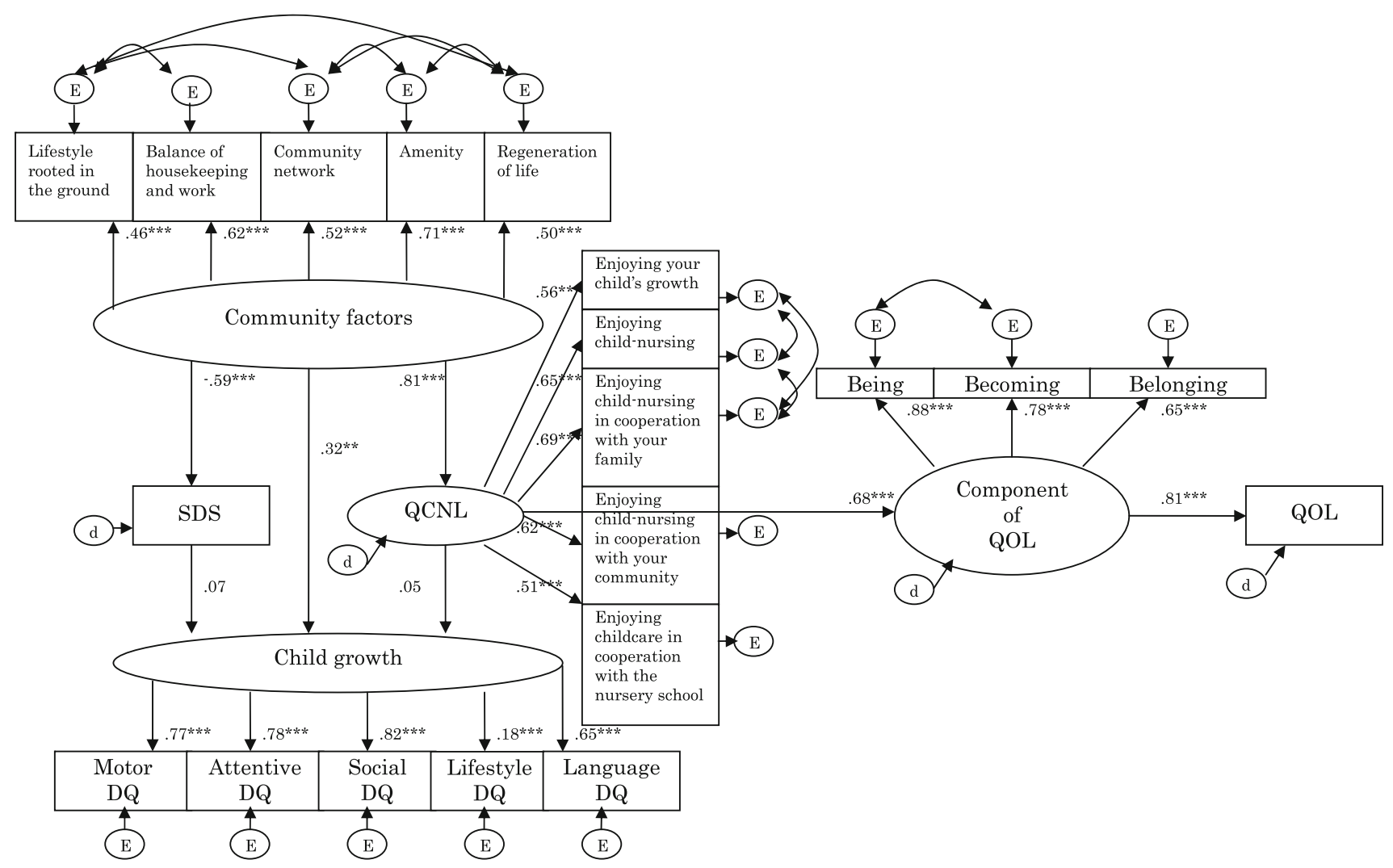

Fig. 2 Structural model with "community factors", QCNL, QOL, and "child growth" by the covariance structural analysis. The real number indicates a standardization of coefficient. $\chi^{2}=687.226$; flexibility $=161, p=0.000 * * *$ Model goodness of fit CFI $=0.923$ RMSEA $=0.058$ 
shown in Table 2, the subjects showed rural characteristics, such as a relatively high number of family members and children, and high rates of subjects within the residential environment is dominant in rural areas, with even City A with a relatively large population being classified as an urban area.

The overall and individual elements of QCNL we developed for our study were shown to have relatively high scores (Table 3). The SDS score was also relatively high (Table 3), and $50.4 \%$ of our subjects were classified with "slight and more advanced depression" ( $>40$ points). Although this situation was not severe in child-nurturing parents in Kumamoto Prefecture in comparison with the results of other research in parents sending their child to nursery schools [21], our result may indicate that childnurturing parents in Kumamoto Prefecture may be suffering from some stress due to conflicts in community life. It is possible, however, the "community factors" may mitigate that stress.

Relationship between "community factors" of childnurturing parents and sound growth of their children

As shown in Table 4, significant correlations were seen between overall "community factors" and infant developmental items with the Tsumori-Inage Infant's Developmental Test $(r=0.12-0.17)$. However, there was no significant correlation between QCNL and items of the Tsumori-Inage Infant's Developmental Test. Next, we found a best fitting model, as shown in Fig. 2. In this model, the item "community factors" was significantly associated with QCNL $(r=0.81)$, SDS $(r=-0.59)$, and "child growth" $(r=0.32)$; in addition, SDS and QCNL were not significantly associated with "child growth". We considered that differences in $r$ values related to "community factors" and "child growth", as determined by Pearson's correlation coefficient in Table $4(r=0.12-0.17)$ or by covariance structural analysis $(r=0.32)$, influenced a number of factors. In Table 4, some factors, such as "number of family members," "number of children," "duration of residence," and "parents' age", were related to "community factors." "Poverty" is another possible factor. Robert et al. showed that being poor affects nearly every aspect of a child's home life [24]. In our study, for ethical issues, the economic situation of each household could not be confirmed. Robert et al. also examined the frequency with which children were exposed to various parental actions, materials, events, and conditions as part of their home environments, and how these exposures related to their well-being. The most consistent relationships found were those between learning stimulation and children's developmental status, with relationships for parental responsiveness and spanking varying as a function of outcome, age, ethnicity, and poverty status [25]. Intelligence in children is known to be closely related to contact with a wide variety of people and exposure to diverse and complex stimulations [22, 23].

Our observations suggest that contact with a wide variety of people may be important for the sound growth of children and that various environmental stimuli, such as participating in community events and bringing children into contact with animals and plants, may also be important. These items are closely related to "community factors."

Our findings also indicate that even for urban residents "community factors" can improve the overall QOL of parents, enabling them to realize a "behavior and lifestyle" favorable for child-nurturing and to reduce their SDS score. It has been established that "community factors", which are indispensable for the child-nurturing environment, can be implemented in any area.

In conclusion, we have clarified the significance of "community factors" in promoting the QCNL of childnurturing parents and sound growth of their children by conducting qualitative and quantitative surveys. Future research should be performed to confirm if the present questionnaire battery is applicable to all regions with various geographical characteristics and to establish the standard score in order to evaluate "community factors" for child-nurturing parents and relations.

Acknowledgments This study was supported by the East Asian Health Promotion Network Center (EAHP-net). The authors are grateful to Dr. Akemi Tomoda (Child Development Research Center, Hukui University) for her useful advice. This study also owes much to the cooperation of working group members, nursery school teachers, and parents. The authors express their profound gratitude to Professor Takashi Miyakita (Kumamoto Gakuen University) for his cooperation in the establishment of this project, Professor Isamu Kaneko (Hokkaido University) for his advice on low-birthrate societies, Professor Makoto Sato (Hokkaido University) for his advice regarding an "agriculture-oriented lifestyle", Professor Yoshitaka Ito (Kumamoto Gakuen University) for his advice on the childcare environment, and Professor Nobuko Takeda (Musashi University) for her advice regarding child-nurturing societies.

\section{Appendix: The questionnaire items and exploratory factor analysis of questionnaire}

Extraction method: principal component analysis; Eigenvalue $>1$; Varimax rotation with Kaiser normalization; sorted by factor names; factor loading $<0.3$ suppressed 


\section{QOL}

The following questions concern your level of satisfaction regarding your daily life and child raising. Circle the appropriate responses.

Points; 5.Significantly satisfied, 4.Slightly satisfied, 3.Undecided, 2.Slightly dissatisfied, 1.Significantly dissatisfied

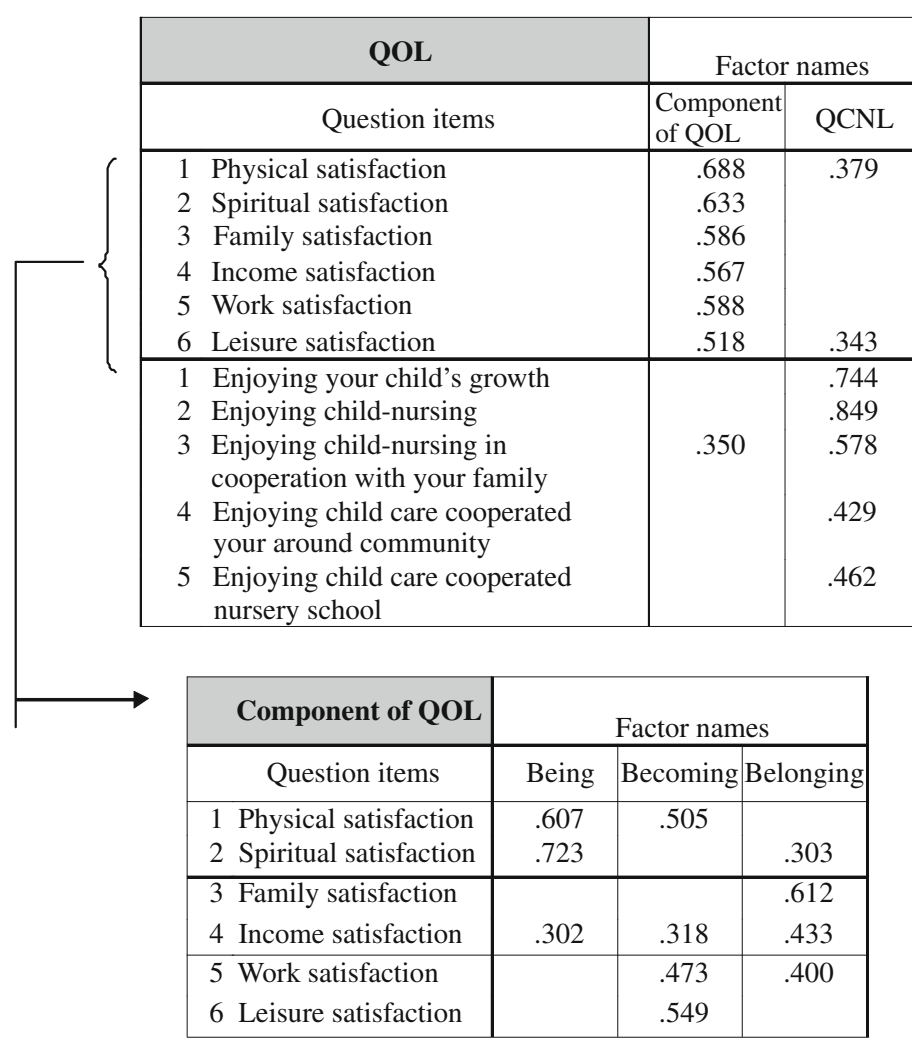

\section{Behavior and lifestyle}

The following questions concern your daily life.

Points; 4.I often do it, 3.I generally do it, 2.I rarely do it, 1.I do not do it at all.

\begin{tabular}{|c|c|c|c|}
\hline Behavior and lifestyle & \multicolumn{3}{|c|}{ Factor names } \\
\hline Question items & $\begin{array}{l}\text { Contact with } \\
\text { the child and } \\
\text { cooperation of } \\
\text { the family }\end{array}$ & \begin{tabular}{ll}
\multicolumn{2}{l}{ Relationship } \\
with a \\
nursery \\
school
\end{tabular} & \begin{tabular}{|l|} 
Association \\
with \\
neighbors
\end{tabular} \\
\hline Do you communicate with your family? & .614 & & \\
\hline $\begin{array}{ll}2 \text { Do you encourage your child(ren) to play } \\
\text { outdoors? }\end{array}$ & & & .454 \\
\hline 3 Do you play with your child(ren)? & .422 & & \\
\hline Are you interested in your child(ren)'s growth? & .507 & & \\
\hline $\begin{array}{ll}5 & \text { Do you raise your child(ren) in cooperation with } \\
\text { your family? }\end{array}$ & 637 & & \\
\hline $\begin{array}{l}6 \text { Do you raise your child(ren) according to certain } \\
\text { principles of parenting? }\end{array}$ & .346 & & .311 \\
\hline 7 Do you actively associate with your neighbors? & & & .733 \\
\hline 8 Do you greet your neighbors? & & & .319 \\
\hline $\begin{array}{l}9 \text { Do you agree with the nursery school's principles } \\
\text { of parenting? }\end{array}$ & & .880 & \\
\hline $\begin{array}{l}\text { Do you talk with the nursery school teacher(s) } \\
\text { about child raising? }\end{array}$ & & .503 & \\
\hline
\end{tabular}




\section{Environmental factors}

The following questions concern your actual "life".

Points; 4.Yes, sufficiently, 3.Yes, to some extent, 2.Yes, but rarely, 1.Not at all

\begin{tabular}{|c|c|c|c|c|c|}
\hline "community factors" & \multicolumn{5}{|c|}{ Factor names } \\
\hline Question items & $\begin{array}{c}\text { Community } \\
\text { network }\end{array}$ & $\begin{array}{c}\text { Balance of } \\
\text { housekeep } \\
\text {-ing and } \\
\text { work }\end{array}$ & $\begin{array}{l}\text { Regenerati } \\
\text {-on of life }\end{array}$ & $\begin{array}{l}\text { Lifestyle } \\
\text { rooted in } \\
\text { the ground }\end{array}$ & Amenity \\
\hline $\begin{array}{l}1 \text { Have you encouraged associations between } \\
\text { your child(ren) and elderly people since } \\
\text { his/her infancy? }\end{array}$ & & & & .718 & \\
\hline $\begin{array}{ll}\text { Have you raised your child(ren) in } \\
\text { cooperation with his/her grandparents? }\end{array}$ & & & & .597 & \\
\hline $\begin{array}{l}3 \text { Do you spend time with your child(ren) with } \\
\text { ease? }\end{array}$ & & .632 & & & \\
\hline $\begin{array}{l}4 \text { Do you manage to have time to play with } \\
\text { your child(ren)? }\end{array}$ & & .786 & & & \\
\hline $\begin{array}{ll}5 \text { Have you developed warm and friendly } \\
\text { relationships with your neighbors? }\end{array}$ & .573 & & & & \\
\hline 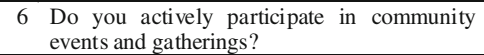 & .789 & & & & \\
\hline 7 Do you actively work as a volunteer? & .578 & & & & \\
\hline $\begin{array}{l}8 \text { In your daily life, do you feel healed by } \\
\text { communing with nature? }\end{array}$ & .302 & .364 & .381 & & .461 \\
\hline $\begin{array}{l}9 \begin{array}{l}\text { Do you teach your child(ren) the preciousness } \\
\text { of life through the life and death of creatures } \\
\text { (such as pets)? }\end{array} \\
\end{array}$ & & & .569 & & \\
\hline $\begin{array}{l}10 \text { Do you grow flowers and/or vegetables with } \\
\text { your child(ren) and experience the joy of } \\
\text { growing and eating them? }\end{array}$ & & & .720 & & \\
\hline
\end{tabular}

\section{Predisposing factors}

The following questions concern your thoughts, knowledge, and attitude.

Points ; 4. Yes, 3. Yes, generally, 2. Not really, 1. Not at all

\begin{tabular}{|c|c|c|c|c|c|}
\hline Predisposing factors & \multicolumn{5}{|c|}{ Factor names } \\
\hline Question items & $\begin{array}{l}\text { Concern } \\
\text { about the } \\
\text { community }\end{array}$ & $\begin{array}{l}\text { Agreement } \\
\text { that } \\
\text { child-nursing } \\
\text { would be } \\
\text { enjoyable }\end{array}$ & \begin{tabular}{|c|} 
Desire or \\
child-nursing \\
participation \\
and \\
cooperation
\end{tabular} & $\begin{array}{l}\text { Knowledge of } \\
\text { how a child } \\
\text { can grow up } \\
\text { healthily }\end{array}$ & $\begin{array}{l}\text { Approach abili } \\
\text { ty of the } \\
\text { nursery } \\
\text { school }\end{array}$ \\
\hline $\begin{array}{l}\text { 1. Do children grow up soundly if their } \\
\text { parents are on good terms with each } \\
\text { other? }\end{array}$ & & & & .485 & \\
\hline $\begin{array}{l}\text { 2. Do you hope to have your child(ren) play } \\
\text { outdoors as much as possible? }\end{array}$ & & & & .346 & \\
\hline $\begin{array}{l}\text { 3. Is reading books to children good for } \\
\text { them? }\end{array}$ & & & & .616 & \\
\hline $\begin{array}{l}\text { 4. Do you try to physically exercise with } \\
\text { your child(ren) as much as possible? }\end{array}$ & & .566 & & & \\
\hline $\begin{array}{l}\text { 5. Do you think thing that child raising is } \\
\text { fun? }\end{array}$ & & .580 & & & \\
\hline $\begin{array}{l}\text { 6. Do you hope to attend your child(ren)'s } \\
\text { presentational activities? }\end{array}$ & & & .381 & & \\
\hline $\begin{array}{l}\text { 7. Does child raising require support from } \\
\text { other people? }\end{array}$ & & & .482 & & \\
\hline $\begin{array}{l}\text { 8. Do you think activities that children are } \\
\text { enjoy best for them? }\end{array}$ & & & .566 & & \\
\hline $\begin{array}{l}\text { 9. Do you try to be understanding regarding } \\
\text { your child(ren)'s feelings? }\end{array}$ & & .389 & .369 & & \\
\hline $\begin{array}{l}\text { 10. Do you value the relationship with your } \\
\text { neighbors? }\end{array}$ & .634 & .396 & & & \\
\hline $\begin{array}{l}\text { 11. Are you acquainted with activities for } \\
\text { promoting local community associations? }\end{array}$ & .731 & & & & \\
\hline $\begin{array}{l}\text { 12. Do you hope to associate with your } \\
\text { neighbors? }\end{array}$ & .674 & & & & \\
\hline $\begin{array}{l}\text { 13. Do you like your child(ren)'s nursery } \\
\text { school? }\end{array}$ & & & & & .426 \\
\hline $\begin{array}{l}\text { 14. Do you know of consulting services and } \\
\text { day nurseries that you can use when you } \\
\text { are tired from child raising? }\end{array}$ & .352 & & & & .412 \\
\hline $\begin{array}{l}\text { 15. Are you acquainted with nursery school } \\
\text { events? }\end{array}$ & & & & & .637 \\
\hline
\end{tabular}




\section{Reinforcing factors}

The following questions concern your family, your child(ren), and people around you.

Points; 4.Yes, always, 3.Yes, sometimes, 2.Not really, 1.Not at all

\begin{tabular}{|c|c|c|c|c|c|}
\hline Reinforcing factors & \multicolumn{5}{|c|}{ Factor names } \\
\hline Question items & $\begin{array}{c}\text { Neighbor } \\
\text { support }\end{array}$ & $\begin{array}{l}\text { Support of } \\
\text { the nursery } \\
\text { school }\end{array}$ & $\begin{array}{l}\text { Family's } \\
\text { support }\end{array}$ & $\begin{array}{l}\text { Childcare } \\
\text { cooperator }\end{array}$ & $\begin{array}{l}\text { Child-nursin } \\
\text { g-friend and } \\
\text { extroversion } \\
\text { of the child }\end{array}$ \\
\hline $\begin{array}{l}\text { 1.Does your family (such as your husband, your } \\
\text { child(ren)'s grandparents, and siblings) support you } \\
\text { mentally? }\end{array}$ & & & .744 & & \\
\hline 2.Do you have anyone to consult about your troubles? & & & .649 & & .343 \\
\hline 3.Does your child(ren) enjoy playing outdoors? & & & & & .342 \\
\hline $\begin{array}{l}\text { 4.Do you have someone who can play with your } \\
\text { child(ren)? }\end{array}$ & & & & .580 & .439 \\
\hline $\begin{array}{l}\text { 5.Do guardians of children of the same age as your } \\
\text { child(ren) talk to you? }\end{array}$ & .362 & & & & .436 \\
\hline $\begin{array}{l}\text { 7.Is there anyone in your immediate circle who } \\
\text { supports you in child raising? }\end{array}$ & & & .335 & .683 & \\
\hline $\begin{array}{l}\text { 8.Is there anyone to whom you can entrust your } \\
\text { child(ren) to care for if necessary? }\end{array}$ & & & & .664 & \\
\hline $\begin{array}{l}\text { 9.Is there a family member who agrees with your } \\
\text { principles of parenting? }\end{array}$ & & & .614 & .338 & \\
\hline $\begin{array}{l}\text { 10.Do any of your neighbors support you in child } \\
\text { raising? }\end{array}$ & .818 & & & & \\
\hline $\begin{array}{l}\text { 11.Do you have any neighbor who associates with both } \\
\text { you and your child(ren)? }\end{array}$ & .870 & & & & \\
\hline $\begin{array}{l}\text { 12.Do you have any neighbor who cares for your } \\
\text { child(ren) when out of your sight? }\end{array}$ & .852 & & & & \\
\hline $\begin{array}{l}\text { 13.Is there any teacher who praises your child(ren) } \\
\text { and encourages you in child raising? }\end{array}$ & .156 & .678 & & & \\
\hline $\begin{array}{l}\text { 14.Is there any teacher at the nursery school you can } \\
\text { consult with ease? }\end{array}$ & & .912 & & & \\
\hline $\begin{array}{l}\text { 15.Have you developed a relationship built on trust } \\
\text { with any nursery school teacher? }\end{array}$ & & .849 & & & \\
\hline $\begin{array}{l}\text { 6. Has your child(ren) grown peacefully, kindly, } \\
\text { cheerfully, and vigorously? }\end{array}$ & deletion & & & & \\
\hline
\end{tabular}

\section{Enabling factors}

The following questions concern your child raising environment.

Points; 4,Yes, sufficiently, 3.Yes, to some extent, 2,Yes, but rarely, 1. Not at all

\begin{tabular}{|c|c|c|c|c|c|}
\hline Enabling factors & \multicolumn{5}{|c|}{ Factor names } \\
\hline Question items & \begin{tabular}{|c|} 
Good \\
relationship \\
with the \\
neighborhood
\end{tabular} & \begin{tabular}{|c|} 
Good \\
relation ship \\
with the \\
nursery \\
school
\end{tabular} & $\begin{array}{l}\text { Use of } \\
\text { information, } \\
\text { tools, and } \\
\text { support } \\
\text { required for } \\
\text { child-nursing }\end{array}$ & \begin{tabular}{|c|} 
Good \\
relationship \\
with the \\
family
\end{tabular} & $\begin{array}{c}\text { Having a } \\
\text { place children } \\
\text { can play } \\
\text { safely }\end{array}$ \\
\hline $\begin{array}{l}\text { 1.Are your family members friendly with each } \\
\text { other? }\end{array}$ & & & & 697 & \\
\hline $\begin{array}{l}\text { 2.Do you have a place/occasion for } \\
\text { parent-child communication? }\end{array}$ & & & & .697 & \\
\hline $\begin{array}{l}\text { 3.Is there a place to play safely in the open in } \\
\text { your neighborhood? }\end{array}$ & & & & & .700 \\
\hline $\begin{array}{l}\text { 4.Do you have teaching materials or tools to } \\
\text { play sports or physical exercises with your } \\
\text { child(ren)? }\end{array}$ & & & .381 & & .366 \\
\hline $\begin{array}{l}\text { 5.Does your child(ren) have any chance to } \\
\text { perform presentational activities either at the } \\
\text { nursery school or home? }\end{array}$ & & & .448 & & \\
\hline $\begin{array}{l}\text { 6.Are you interested in your child(ren)'s } \\
\text { growth and read books and magazines or use } \\
\text { the Intemet or other media for information } \\
\text { on parenting? }\end{array}$ & & & .546 & & \\
\hline $\begin{array}{l}\text { 7.Is there anyone you can consult in your } \\
\text { immediate circle if necessary? }\end{array}$ & & & .416 & & \\
\hline $\begin{array}{l}\text { 8.Can you use any home- or child-care support } \\
\text { service when you have troubles with child } \\
\text { raising? }\end{array}$ & & & .349 & & \\
\hline $\begin{array}{l}\text { 9. When you teach your child(ren) manners and } \\
\text { customs, do you also tell him/her your } \\
\text { thoughts? }\end{array}$ & & & .346 & & \\
\hline $\begin{array}{l}\text { 10.Are there social gatherings in your } \\
\text { neighborhood? }\end{array}$ & .391 & & .358 & & \\
\hline 11.Do your neighbors talk to you? & .895 & & & & \\
\hline $\begin{array}{l}\text { 12.Are you on friendly terms with your } \\
\text { neighbors? }\end{array}$ & .824 & & & & \\
\hline $\begin{array}{l}\text { 13.Can you entrust your child(ren) to the } \\
\text { nursery school without worrying? }\end{array}$ & & .838 & & & \\
\hline $\begin{array}{l}\text { 14.Is there any nursery school where your } \\
\text { child(ren) enjoys going? }\end{array}$ & & .792 & & & \\
\hline $\begin{array}{l}\text { 15.Do you think that the nursery school fee is } \\
\text { not placing severe strain on your household } \\
\text { finances? }\end{array}$ & deletion & & & & \\
\hline
\end{tabular}




\section{References}

1. Ministry of Health, Labour and Welfare. Annual report on health, and welfare for 2008-2009 (in Japanese). Tokyo: Ministry of Health, Labour and Welfare. 2009.

2. Miyagi Y, Okuno M, Nakatsuka M. Sociological factors in pregnant employees and declining birthrate: family income and financial aid (in Japanese). Matern Health. 2008;49(2):253-60.

3. Sato H, Suzuki Y. Consciousness and difficulty of child care by mothers of infants-comparative study on factors causing declining birth rate in Aomori Prefecture and Hokkaido (in Japanese). J Jpn Health Sci. 2003;9(2):31-43.

4. Saito S, Hoshiyama Y, Miyahara S. Studies on the personal and social generativity in the low fertility society: a survey on the attitude toward nurturing the next generation (in Japanese). J Natl Inst Public Health. 2004;53(3):218-27.

5. Kaneko I. Conquest and the subject of a decrease in the birthrate (in Japanese). JJPA. 2005;30:18-23.

6. Kaneko I. Some sociological comments on "an aged society with a declining birthrate" (in Japanese). JSR. 2005;56(1):93-111.

7. Fujii E, Iwasaki Y, Mishima K, Kweon H, Chiu H, Suda A, et al. Study on use of landscape and plants resource to medicine treatment (in Japanese). Hortic Res. 2006;60:109-15.

8. Endo M, Mishima K, Fujii E. The effect of contemplating plants in planter, on EEG, ECG, heart rate variability and emotion (in Japanese). JJSPPR. 2001;1(1):21-4.

9. Ueda K, Ueda A, Miyakita T, Harada K, Ohmori S, Wei C, et al. Community-based analysis of the factorial structures of the recent increase in low birthweight infants. Environ Health Prev Med. 2000;5(3):118-26.

10. Sharon V, Jeanne SS, Jane S. Focus group interviews in education and psychology(in Japanese). Tokyo: Keiougijukudaigakushuppankai; 1996.

11. Pope C, Mays N. Qualitative research in health care(in Japanese). Tokyo: Igakushoin; 2001.

12. Kerr E, Asch S, Hamilton E, McGlynn E. Quality of care for cardiopulmonary conditions. A review of the literature and quality indicators. Santa Monica: RAND HEAKTH; 2000.

13. Green LW, Kreuter MW. Health program planning. An educational and ecological approach, 4th edn (in Japanese). Tokyo: Igakushoin; 2005 (translated)
14. Renwick R, Brown I, Negler M. Quality of life in health promotion and rehabilitation. Thousand Oaks: Sage Publications; 1996.

15. Hukuda K, Kobayashi S. Hand book of self-rating depression scale Japanese version (in Japanese). Kyoto: Sankyobo; 1983.

16. Tsumori M, Inage K. Determination of psychological growth for infants 0-3 years old (in Japanese). Tokyo: Dainippontosho; 1961.

17. Tsumori M, Isobe K. Determination of psychological growth for infants 3-7 years old (in Japanese). Tokyo: Dainippontosho; 1965.

18. The 53th statistical yearbook of agriculture, forestry and fisheries in Kumamoto (in Japanese). Kyushu Regional Agricultural Administration Office Statistics Department. 2007.

19. Motohashi Y, Kaneko Y, Sasaki H. Community-based suicide prevention program in Japan using a health promotion approach. Environ Health Prev Med. 2004;9:3-8.

20. Kaneko Y, Motohashi Y, Sasaki H, Yamaji M. Prevalence of depressive symptoms and related risk factors for depressive symptoms among elderly persons living in a rural Japanese community: cross-sectional study. Community Ment Health J. 2007;43:583-90.

21. Okamoto K. A study on stress and depressive symptoms in parents of nursery school children-a comparison between fathers and mothers (in Japanese). Bull Kibi Int Univ Dep Health Sci. 2008;13:11-7.

22. Schaefer E. Assessment of parent competence and child-nursing. In: Proc 5th Int Conf of Early Identification of Children at Risk. Predictors of Child Development. Denver: University of Colorado; 1987.

23. Yarrow J, Rubenstein L, Pedersen A, Jankowski J. Dimensions in early stimulation and their differential effects on infant development. MPQ. 1972;18:205-18.

24. Robert H, Robert F, Harriette P, Cynthia G. The home environments of children in the United States part I: variations by age. Child Dev. 2001;72(6):1844-67.

25. Robert H, Robert F, Margaret B, Harriette P, Cynthia G. The home environments of children in the United States Part II: relations with behavioral development through age thirteen. Child Dev. 2001;78(6):1868-86. 